\title{
Disruption in Candida albicans of the TPS2 gene encoding trehalose-6-phosphate phosphatase affects cell integrity and decreases infectivity
}

\author{
Oscar Zaragoza, ${ }^{1} \dagger$ Claudio de Virgilio, ${ }^{2} \ddagger$ José Pontón ${ }^{3}$ \\ and Carlos Gancedo'
}

\begin{abstract}
Author for correspondence: Carlos Gancedo. Tel: +34 91 5854620. Fax: +34 915854587. e-mail: cgancedo@iib.uam.es
\end{abstract}

1 Instituto de Investigaciones Biomédicas 'Alberto Sols' CSIC-UAM, Unidad de Bioquímica y Genética de Levaduras, 28029 Madrid, Spain

2 Botanisches Institut, Universität Basel, Hebelstr 1, CH-4056 Basel, Switzerland

3 Departamento de Inmunología, Microbiología y Parasitología, Facultad de Medicina y Odontología, Universidad del País Vasco, 48080 Bilbao, Spain

\begin{abstract}
The gene CaTPS2 encoding trehalose-6-phosphate (T6P) phosphatase from Candida albicans has been cloned and disrupted in this organism. The Catps2/Catps2 mutant did not accumulate trehalose but accumulated high levels of T6P. Disruption of the two copies of the CaTPS2 gene did not abolish growth even at $42{ }^{\circ} \mathrm{C}$, but decreased the growth rate. In the stationary phase, the Catps2/Catps 2 mutant aggregated, more than $50 \%$ of its cells became permeable to propidium iodide and a large amount of protein was found in the culture medium. Aggregation occurred only at pH values higher than 7 and was avoided by osmoprotectants; it was never observed during the exponential phase of growth. The mutant formed colonies with a smooth border on Spider medium. Mice inoculated with $1.5 \times 10^{6}$ c.f.u. of wild-type cells died after 8 days, while $80 \%$ of those inoculated with the same number of c.f.u. of the Catps2/Catps2 mutant survived for at least 1 month.

Reintroduction of the wild-type CaTPS2 gene in the Catps2/Catps2 mutant abolished the phenotypes described. It is hypothesized that the accumulation of T6P interferes with the assembly of a normal cell wall.
\end{abstract}

Keywords : cell wall, aggregation, stress, antifungals

\section{INTRODUCTION}

Infections by opportunistic pathogens are of increasing clinical importance, particularly as the population of immunocompromised patients increases. Systemic infections by the yeast Candida albicans rank among the leading causes of death by microbial infections (de Pauw \& Meunier, 1999; Edwards, 1991; Verduyn Lunel et al., 1999). Effective drugs are available for the treatment of candidiasis (Herbrecht et al., 1999; Martin, 1999), but the increasing prevalence of resistant strains indicates an urgent need for new antifungal agents (Monk \& Perlin, 1994). Since the infective agent and the host are eukaryotic organisms sharing many pathways, specific targets should be looked for among those activities

†Present address: Albert Einstein College of Medicine, 1300 Morris Park Avenue, Bronx, NY 10461, USA.

¥Present address: Département de Biochimie Médicale, Centre Médical Universitaire, 1211 Geneva 4, Switzerland.

Abbreviation: T6P, trehalose 6-phosphate.

The EMBL accession number for the sequence reported in this paper is AJ242990. exclusive to the micro-organism. In this context, the pathway of synthesis of trehalose appears to be a promising candidate, since this disaccharide plays important roles in many micro-organisms (François et al., 1997; Van Laere, 1989) and has not been found in mammals. Trehalose biosynthesis implicates the formation of trehalose 6-phosphate (T6P) catalysed by T6P synthase (EC 2.4.1.15) followed by hydrolysis of T6P by T6P phosphatase (EC 3.1.3.12) (Cabib \& Leloir, 1958). Disruption of the gene encoding T6P phosphatase, named TPS2 in Saccharomyces cerevisiae or orlA in Aspergillus nidulans, makes these organisms thermosensitive (Borgia et al., 1996; De Virgilio et al., 1993). We reasoned that if disruption of the corresponding gene in C. albicans produced a similar phenotype, inhibitors of the T6P phosphatase activity could be interesting drugs for the treatment of candidiasis in mammals. Following this idea, we have cloned the TPS2 gene from C. albicans and studied the consequences of its disruption. We report in this article that disruption of CaTPS2 leads to aggregation of the cells in stationary phase and greatly decreases infectivity of C. albicans in mice. 


\section{METHODS}

Strains, growth conditions and molecular biology procedures. The strains used in this work are shown in Table 1. The yeasts were grown with shaking at 30,37 or $42{ }^{\circ} \mathrm{C}$ in $1 \%$ yeast extract, $2 \%$ peptone (YP) or in a synthetic medium (YNB, Difco yeast nitrogen base) with the adequate auxotrophic requirements and either glucose, glycerol or ethanol at $2 \%$. Hyphae formation was induced as described by Zaragoza et al. (1998). Filamentation was examined on Spider medium (Liu et al., 1994) in plates of $9 \mathrm{~cm}$ diameter with $20 \mathrm{ml}$ medium and 50-100 colonies per plate. When needed, media were buffered with $0 \cdot 2 \mathrm{M}$ MES, $\mathrm{pH}$ 5, or $0 \cdot 2 \mathrm{M}$ HEPES, $\mathrm{pH} 7 \cdot 5$.

Sac. cerevisiae was transformed as described by Gietz et al. (1992) and C. albicans either by electroporation (Kohler et al., 1997) or using protoplasts (Kurtz et al., 1986). Recombinant DNA manipulations were done as described by Sambrook et al. (1989) and DNA probes were labelled using the Pharmacia oligolabelling kit. Genomic DNA was obtained from cells broken with glass beads as described by Hoffman \& Winston (1987).

DNA sequencing and sequence analyses. Sequences were obtained from double-stranded plasmid DNA by the use of the cycle sequencing method and the ABI PRISM 310 capillary sequencer (Perkin Elmer Applied Biosystems). Sequences were analysed by using standard programs.

Isolation of the C. albicans TPS2 gene. The temperaturesensitive Sac. cerevisiae tps2 strain YSH 6.106-8C was transformed with a C. albicans genomic DNA library in YEp322 (a gift of C. Nombela and J. Pla, Madrid, Spain). About $10^{6}$ transformants were plated on glucose synthetic medium and incubated at $38.6^{\circ} \mathrm{C}$. Plasmids isolated from positive colonies were tested by PCR using two degenerate oligonucleotides: 5'-GATTACGATGG[CT]AC[CT][CT]T[AGT]AC[CT]CC[AG]AT[CT]GT-3' and 5'-GGACGAACTTC[AG]A[GT][AG]TT[ACGT]GC[CT]TT[ACGT]CC-3', corresponding to highly conserved sequences from known genes encoding T6P phosphatases. A PCR reaction using these primers and DNA from the genomic library mentioned above yielded a fragment of $0.45 \mathrm{~kb}$ with sequence similarity to T6P-phosphatase-encoding genes; the same fragment was obtained with DNA of the isolated plasmids. Plasmid YEp352CaTPS2-1 carried a DNA segment of 3822 bp containing the entire CaTPS2 gene, including $700 \mathrm{bp}$ upstream of the putative initiation codon and $380 \mathrm{bp}$ after the stop codon. The sequence of this fragment is available at the EMBL database under accession no. AJ242990.

Chromosomal disruption of the CaTPS2 gene. The CaTPS2 gene was disrupted with CaURA3 and CaHIS1 using two disruption cassettes (Fig. 1a). The one with CaURA3 was constructed as follows: a $4 \mathrm{~kb} \mathrm{BamHI-BglII}$ fragment from pCUB6K1 (C. San-José, J. Pla \& C. Nombela, unpublished), a derivative of pCUB6 (Fonzi \& Irwin, 1993) containing the hisG-CaURA3-hisG blaster cassette (Fonzi \& Irwin, 1993), was inserted into the unique BamHI site from plasmid YEp352-TPS2-1 to give pOZ11-3. To construct the disruption cassette with CaHIS1, a $1.5 \mathrm{~kb}$ BamHI-BamHI fragment from p34HHIS1 (given by J. Pla) was ligated into the unique Bam HI site from plasmid YEp352-TPS2-1 to produce pOZ11-4. To interrupt the corresponding genomic loci in C. albicans the plasmids were digested with HindIII and the digestion products introduced into the yeast by electroporation. Introduction of the digestion products of pOZ11-3 into C. albicans strain RM1000 produced strain LOZ184, introduction of those of plasmid pOZ11-4 into strain LOZ184 gave strain LOZ200 and introduction of the same products into strain RM1000 provided strain LOZ183. Correct insertion of the disruption cassette was checked by PCR and Southern analysis (Fig. 1b). C. albicans LOZ250 was obtained by popout of the URA3 gene from strain LOZ200 after selection on YNB glucose plates with $20 \mu \mathrm{g}$ uridine $\mathrm{ml}^{-1}$ and $0.5 \mathrm{mg}$ 5-fluoroorotic acid $\mathrm{ml}^{-1}$.

Reintroduction of the CaTPS2 gene into C. albicans. To reintroduce the CaTPS2 gene into a C. albicans tps $2 / t p s 2$

Table 1. Yeast strains used in this work

Construction of C. albicans strains LOZ183, LOZ184, LOZ200, LOZ250 and LOZ252 is described in Methods.

\begin{tabular}{|c|c|c|}
\hline Strain & Genotype & Reference \\
\hline Sac. cerevisiae YSH 6.106-8C & MATa ade2-1 his3-11,15 leu2-3,112 trp1-1 ura3-1 can1-100 tps2::LEU2 & Reinders et al. (1997) \\
\hline Sac. cerevisiae CJM291 & $\begin{array}{l}\text { MATa leu2-1 ura3-52 lys2 hxk1::LEU2 hxk2::LEU2 glk1::LEU2/ } \\
\text { pDB20-YlcHXK1 }\end{array}$ & Petit \& Gancedo (1999) \\
\hline C. albicans SC5314 & $\frac{U R A 3 \text { HIS1 TPS2 }}{\text { URA3 HIS1 TPS2 }}$ & Gillum et al. (1984) \\
\hline C. albicans RM1000 & $\frac{\text { ura } 3:: \text { imm } 434 \text { his } 1:: \text { his } G \text { TPS2 }}{\text { ura3::imm } 434 \text { his } 1:: \text { his } G \text { TPS2 }}$ & Negredo et al. (1997) \\
\hline C. albicans LOZ183 & $\frac{\text { ura3::imm } 434 \text { his } 1:: \text { his } G \text { tps } 2:: \text { HIS1 }}{\text { ura3::imm } 434 \text { his } 1:: \text { his } G \text { TPS } 2}$ & This work \\
\hline C. albicans LOZ184 & $\frac{\text { ura3::imm } 434 \text { his } 1:: \text { his } G \text { tps } 2:: \text { his } G-C a U R A 3-\text { his } G}{\text { ura3::imm } 434 \text { his } 1: \text { his } G \text { TPS2 }}$ & This work \\
\hline C. albicans LOZ200 & $\frac{\text { ura3::imm } 434 \text { his } 1:: \text { his } G \text { tps } 2:: \text { his } G-C a U R A 3-\text { is } G}{\text { ura3::imm } 434 \text { his } 1:: \text { his } G \text { tps } 2:: H I S 1}$ & This work \\
\hline C. albicans LOZ250 & $\frac{\text { ura3::imm } 434 \text { his } 1:: \text { his } G \text { tps } 2:: \text { his } G}{\text { ura3::imm } 434 \text { his } 1:: \text { his } G \text { tps } 2:: H I S 1}$ & This work \\
\hline C. albicans LOZ252 & $\frac{\text { ura3::imm } 434 \text { his } 1:: \text { his } G \text { tps } 2:: \text { his } G / p O Z 11-6}{\text { ura3::imm } 434 \text { his } 1:: \text { hisG tps } 2:: H I S 1}$ & This work \\
\hline
\end{tabular}


(a)

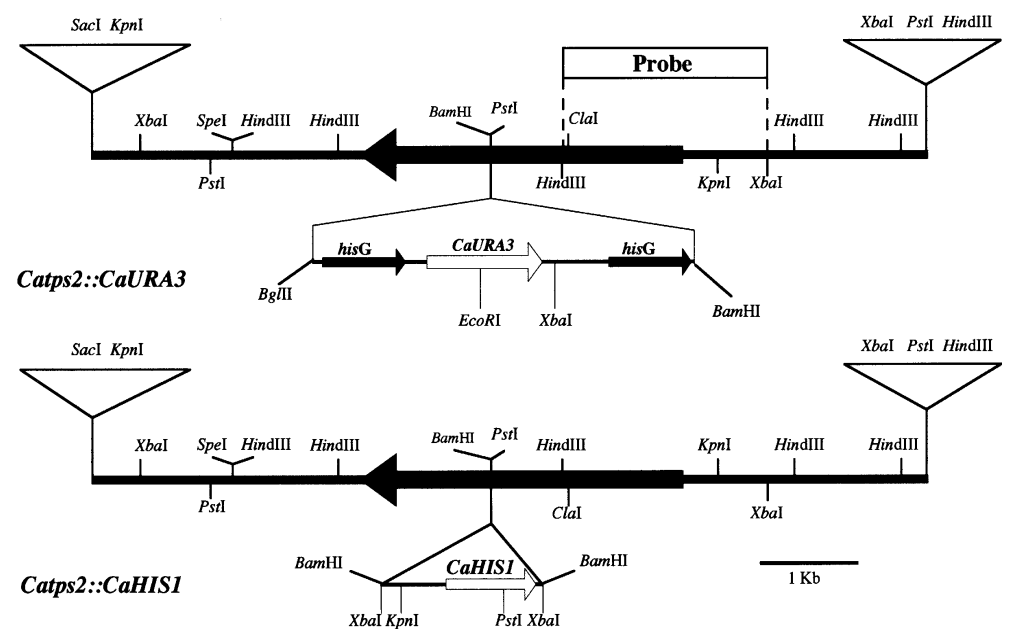

(b)

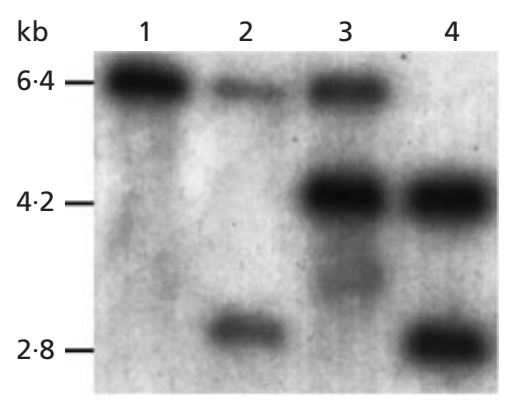

Fig. 1. Disruption of the CaTPS2 gene and Southern analysis of Catps2/Catps2 disruptants. (a) Disruption of CaTPS2 with CaURA3 and CaHIS1 (see Methods for details of construction). The CaTPS2 gene and its direction of transcription is indicated by the thick black arrow. (b) Southern analysis of the chromosomal disruption of CaTPS2. The $2 \mathrm{~kb}$ Clal-Xbal fragment indicated in (a) was used as probe. Genomic DNA was digested with Xbal. Lanes: 1, CaTPS2/Catps2 (SC5314); 2, CaTPS2/Catps2::CaHIS1 (LOZ183); 3, CaTPS2/Catps2::hisG-CaURA3-hisG (LOZ184); 4, Catps2::CaHIS1/Catps2::hisGCaURA3-hisG (LOZ200). Sizes of the fragments are indicated on the left side of the figure.

A

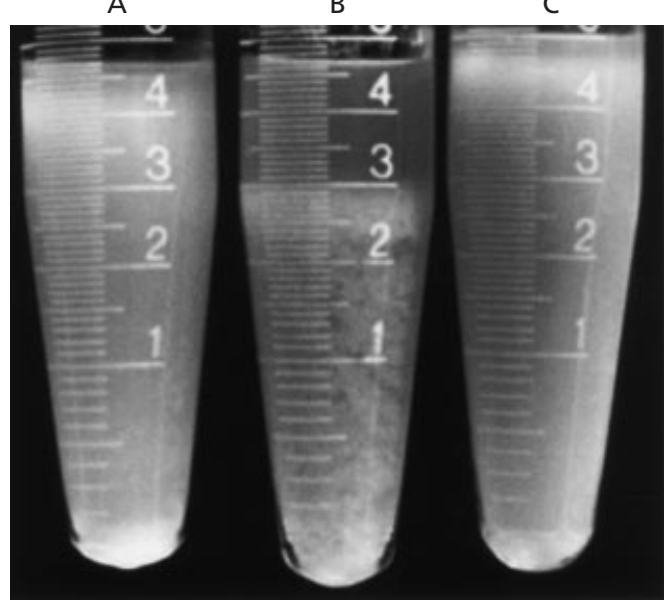

Fig. 2. Aggregation of C. albicans Catps2/Catps2 mutants. Cultures from (A) a wild-type strain (SC5314), (B) a Catps2/Catps2 mutant (LOZ200) and (C) a Catps2/Catps2 mutant (LOZ250; (C) with a reintroduced CaTPS2 gene (pOZ11-6) were grown in YPD at $37{ }^{\circ} \mathrm{C}$ until stationary phase. Aliquots of each culture were transferred to graduate tubes and photographed after $10 \mathrm{~min}$ standing at room temperature.

mutant, plasmid pOZ11-6 was constructed. Briefly, plasmid pOZ11-2 was obtained by ligation of a $4 \mathrm{~kb}$ SpeI (bluntended)-XbaI fragment from plasmid YEp352-TPS2-1 into YEp352 (Hill et al., 1986) digested with XbaI and SmaI. The CaTPS2 gene was excised by digestion with $S c a \mathrm{I}$ and $\mathrm{XbaI}$ and subcloned into YCplac111 (Gietz \& Sugino, 1988) digested with the same enzymes, to yield pOZ11-5. A 4 kb XbaI-KpnI fragment was ligated into the C. albicans vector pLC14 carrying the CaURA3 marker (J. F. García-Bustos unpublished) digested with the same enzymes. The resulting plasmid, pOZ11-6, was introduced into C. albicans LOZ250 using protoplast transformation to give strain LOZ252.

Determination of trehalose and T6P. Trehalose was assayed after hydrolysis with trehalase as described by Blázquez et al. (1994a), and T6P by measuring the specific inhibition of Yarrowia lipolytica hexokinase as described by Blázquez et al. (1994b). The Y. lipolytica hexokinase needed was obtained from Sac. cerevisiae CJM291 (Petit et al., 1996), a strain lacking all glucose-phosphorylating enzymes carrying plasmid pDB20-YlcHXK1 (Petit \& Gancedo, 1999). In some cases, T6P was assayed by HPLC as described by De Virgilio et al. (1993).

Analysis of proteins in culture medium. Cultures were centrifuged and the supernatants collected. Trichloroacetic acid was added at a final concentration of $10 \%$ and the mixture was kept at $4{ }^{\circ} \mathrm{C}$ for $15 \mathrm{~min}$, centrifuged at 13000 r.p.m. for $15 \mathrm{~min}$ in an Eppendorf microcentrifuge and the precipitate resuspended in Laemmli reagent (Laemmli, 1970). The samples were applied to an SDS-PAGE (10\%) gel and stained with Coomassie blue. To detect glycosylated proteins, PAS staining was performed as described by Kapitany \& Zebrowsky (1973).

For analysis of intracellular proteins, cell-free extracts were obtained as described by Blázquez et al. (1993) and proteins were assayed using the commercial Pierce reagent.

Propidium iodide staining. A $25 \mu \mathrm{l}$ sample of a culture was centrifuged and the cells were resuspended in $200 \mu \mathrm{l}$ PBS (Sambrook et al., 1989) to which $13 \mu$ propidium iodide $\left(50 \mu \mathrm{g} \mathrm{ml}^{-1}\right)$ was added. The cells were then examined under a fluorescence microscope.

Preparation of samples for electron microscopy. For scanning electron micrographs, samples were prepared as described by 

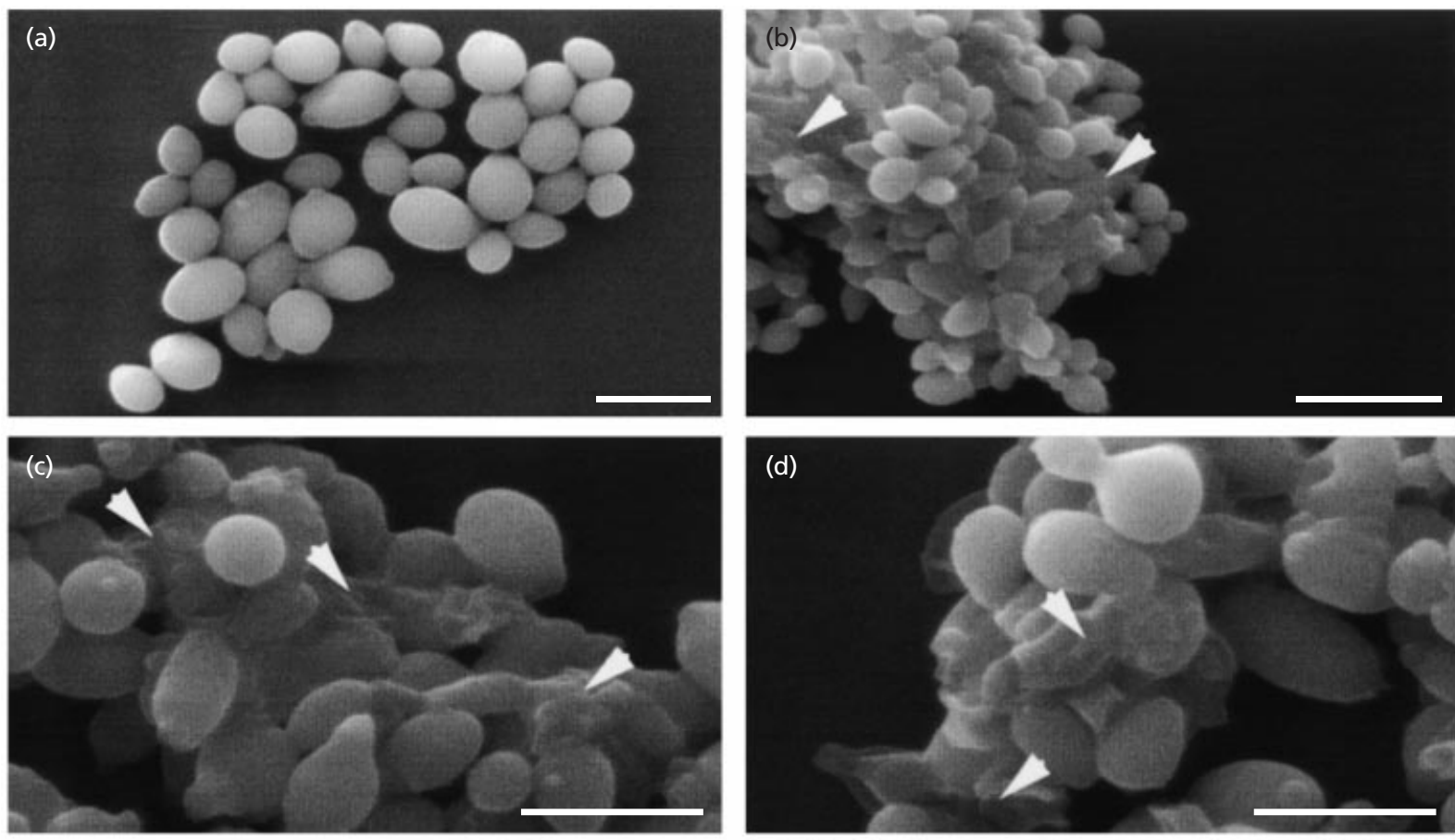

(e)
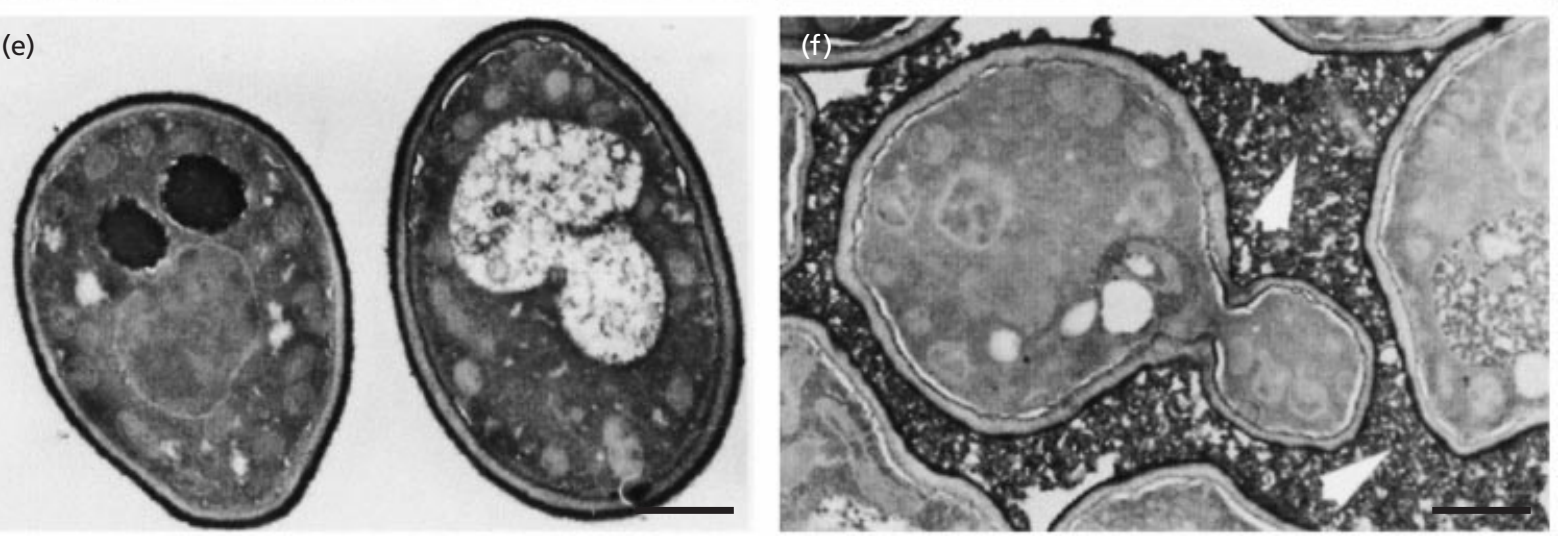

Fig. 3. Electron microscopy of a C. albicans Catps2/Catps2 mutant. Cultures of a wild-type strain (SC5314) and a Catps2/Catps2 mutant (LOZ200) were grown in YPD at $37^{\circ} \mathrm{C}$ until stationary phase. Scanning electron microscopy (a-d) and transmission electron micrographs (e, f) were performed as described in Methods. (a, e) Wild-type; (b-d, f) Catps2/Catps2 mutant. Observe the material surrounding the mutant cells (marked with white arrows in $c, d$ and $f$ ). Bars: a, c, d, $5 \mu \mathrm{m} ; \mathrm{b}, 10 \mu \mathrm{m} ; \mathrm{e}, 800 \mathrm{~nm} ; \mathrm{f}, 700 \mathrm{~nm}$.

Herrero et al. (1999) and for transmission electron micrographs as described by Wright et al. (1988).

Virulence in mice. Yeasts were grown on Sabouraud Dextrose agar (Difco) at $37^{\circ} \mathrm{C}$ for $24 \mathrm{~h}$, washed with $0.85 \% \mathrm{NaCl}$ and resuspended in the same solution. The number of cells to be inoculated in the mice was determined by counting the cells in an haemocytometer and the viability (c.f.u.) was checked by plating the suspension onto Sabouraud Dextrose Agar plates. In these conditions no appreciable aggregation was observed and a good agreement between c.f.u. data and haemocytometer counting was observed. Groups of 10 female mice (BALB/c, 6-8 weeks old, 25-30 g wt) were inoculated in the lateral caudal vein with $1.5 \times 10^{6}$ viable $C$. albicans cells of each strain and observed for 1 month. To determine the c.f.u. in the mice, each organ was removed, weighed and homogenized in $0.85 \% \mathrm{NaCl}$. Dilutions were plated on Sabouraud Dextrose at $30^{\circ} \mathrm{C}$ and colonies were counted after $48 \mathrm{~h}$.
Differences in c.f.u. were analysed by the statistical MannWhitney $U$ test and considered statistically significant at a $P<0 \cdot 05$.

\section{RESULTS}

\section{Isolation and characterization of the CaTPS2 gene}

The C. albicans TPS2 gene was isolated by complementation of the temperature-sensitive growth of an Sac. cerevisiae tps 2 mutant (see Methods). The complementation brought about a drastic decrease in the intracellular concentration of T6P in the transformed cells (in stationary phase from $0 \cdot 104 \mathrm{mM}$ in the tps 2 mutant to $0.015 \mathrm{mM}$ in the transformant) and in cells subjected to a heat shock at $42{ }^{\circ} \mathrm{C}$ (from $0.143 \mathrm{mM}$ in the tps 2 mutant to $0.022 \mathrm{mM}$ in the transformant). These results indicate 

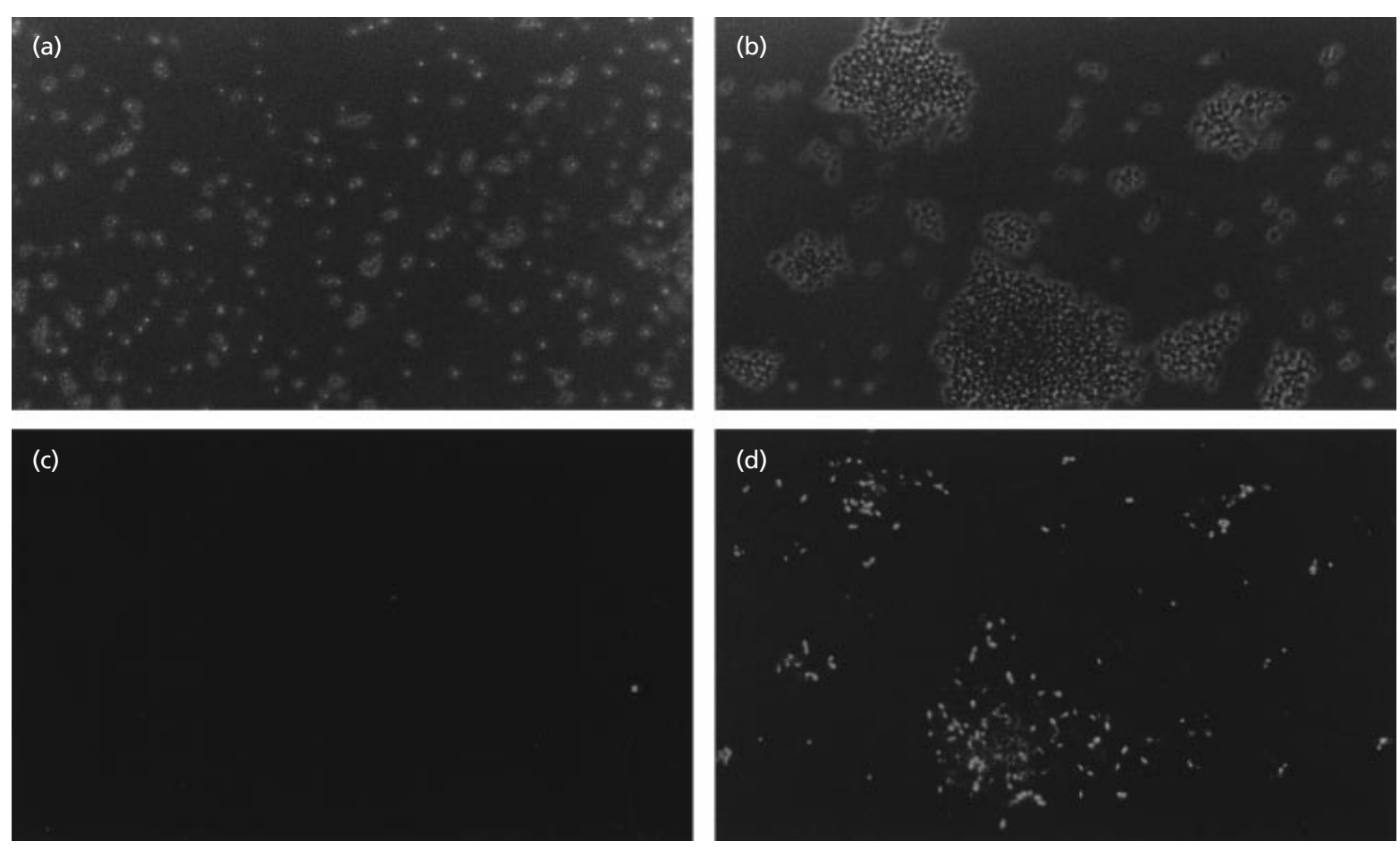

Fig. 4. Uptake of propidium iodide by Catps2/Catps2 mutants. Wild-type (SC5314) (a, c) and Catps2/Catps2 mutant (LOZ200) $(b, d)$ cells were grown in YPD until stationary phase and treated with propidium iodide as described in Methods. (a, b) Phase-contrast micrographs; $(c, d)$ propidium iodide fluorescence micrographs.

that the cloned fragment encodes a protein with phosphatase activity against T6P. When the DNA inserted in the plasmid was sequenced, we found an ORF whose predicted protein sequence had high similarity with T6P phosphatases from other organisms: $67 \%$ with the protein of Sac. cerevisiae (De Virgilio et al., 1993), 53\% with that of Schizosaccharomyces pombe (Franco et al., 2000) and $73 \%$ with that of A. nidulans (Borgia et al., 1996). Analysis of the DNA sequence up to $700 \mathrm{bp}$ upstream of the putative CaTPS2 start codon revealed the existence at positions -91 and -267 of CCCCT motifs that are found in most Sac. cerevisiae genes with stress-controlled transcription (Kobayashi \& McEntee, 1993; Marchler et al., 1993). The orthologous ScTPS2 gene has four to five such stress responsive elements (STRE) in its promoter (Gounalaki \& Thireos, 1994; Varela et al., 1995).

\section{Effects of the disruption of the CaTPS2 gene}

The Catps2/Catps2 disrupted strain did not accumulate trehalose after a heat shock at $42{ }^{\circ} \mathrm{C}$. Throughout growth, the concentration of T6P in the mutant was $1 \mathrm{nmol}$ (mg dry wt $)^{-1}$ during the exponential phase and $3 \mathrm{nmol}(\mathrm{mg} \text { dry } \mathrm{wt})^{-1}$ in the stationary phase, while in the wild-type it was below our detection level $(0.5 \mathrm{nmol})$. These results strongly indicate that there is only one gene encoding T6P phosphatase in C. albicans.

The Catps2/Catps2 mutant grew at $37^{\circ} \mathrm{C}$ and even at $42{ }^{\circ} \mathrm{C}$ in YP-glucose (YPD), although slower than the wild-type. Generation times at $37^{\circ} \mathrm{C}$ were $60 \mathrm{~min}$ for the wild-type and $80 \mathrm{~min}$ for the mutant, and $80 \mathrm{~min}$ for the wild-type and $130 \mathrm{~min}$ for the mutant at $42{ }^{\circ} \mathrm{C}$. In contrast to the wild-type, the mutant cells formed aggregates in stationary phase (Fig. 2). These aggregates were not dispersed by washing with $0.25 \mathrm{M}$ EDTA, a treatment that disperses flocks in Sac. cerevisiae (Stratford, 1989), but they were dispersed by a mild sonication or by a $10 \mathrm{~min}$ treatment with $0 \cdot 2 \mathrm{mg}$ Zymolyase $\mathrm{ml}^{-1}$ that did not affect cell integrity. Reintroduction of an intact CaTPS2 caused the disappearance of the aggregation phenotype, showing that the effects observed were due to the absence of a CaTPS2 gene (Fig. 2). Electron microscopic examination of the mutant cells did not show marked morphological abnormalities in the aggregated cells, but a material surrounding them was observed (Fig. 3). This material was not seen in preparations from exponential-phase cells when aggregation was not observed (results not shown).

Aggregation occurred independently of the carbon source in the media. We observed that whenever aggregation occurred, the final $\mathrm{pH}$ of the media was $>7$. If media were buffered at $\mathrm{pH} 5$, aggregation was not observed. We did not observe aggregation during the exponential phase of growth, even in media buffered at $\mathrm{pH} 7 \cdot 5$.

More than $50 \%$ of stationary-phase Catps2/Catps2 cells were permeable to propidium iodide, while less than $1 \%$ wild-type cells from the same growth phase took up the dye (Fig. 4), indicating that the mutant had 

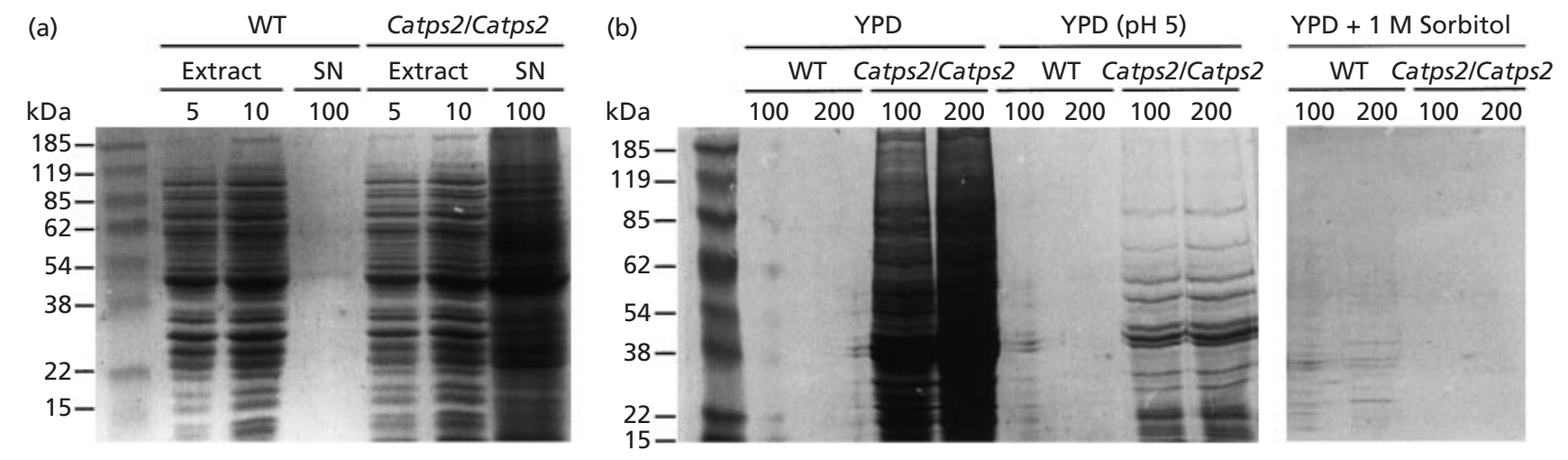

Fig. 5. Analysis of proteins in culture medium. (a) Wild-type (SC5314; WT) and a Catps2/Catps2 mutant (LOZ200) were grown in YPD at $37^{\circ} \mathrm{C}$ until stationary phase and samples were harvested by centrifugation. Proteins in $100 \mu$ of supernatant (SN) were precipitated as described in Methods. The cells were extracted and proteins were determined in the extracts as described in Methods. Intracellular proteins ( 5 and $10 \mu \mathrm{g}$ ) from the corresponding yeast were applied to the gel. (b) Wild-type (SC5314) and a Catps2/Catps2 mutant (LOZ200) were grown under the conditions indicated and treated as described in (a). Proteins in 100 and $200 \mu \mathrm{l}$ of the supernatants were precipitated as described in Methods. The figures over each lane indicate the amount of supernatant precipitated. Proteins were stained with Coomassie blue.
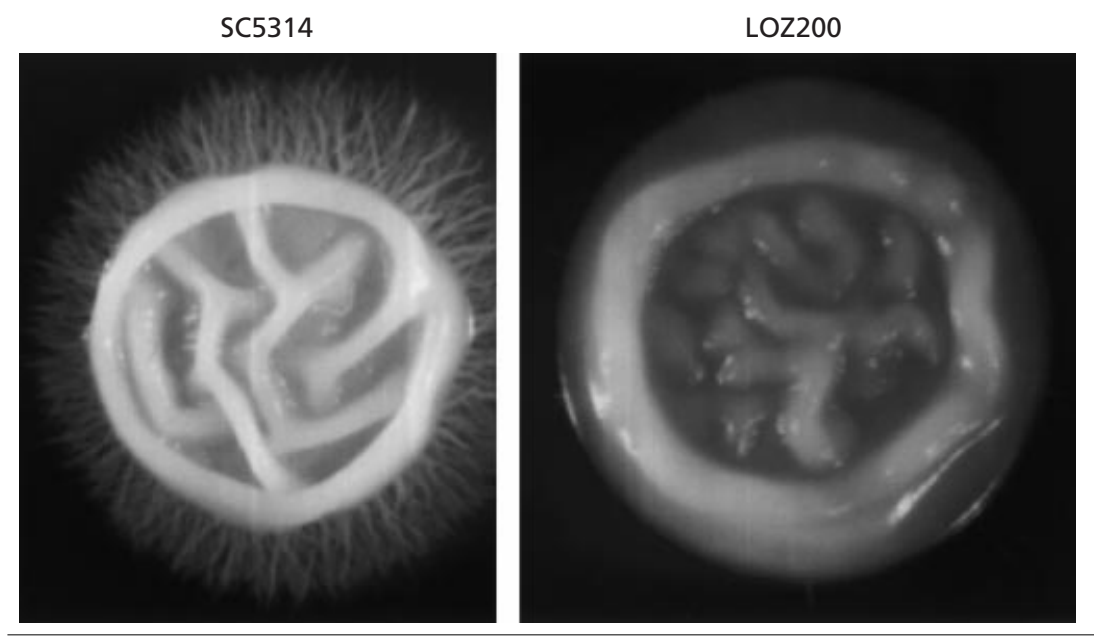

Fig. 6. Colony morphology of C. albicans wild-type and Catps2/Catps2 mutant cells. C. albicans wild-type (SC5314) and a Catps2/Catps2 mutant (LOZ200) were grown in YPD and spread on Spider medium as described in Methods. Photographs were taken after 7 days at $37^{\circ} \mathrm{C}$.

a defect in cell integrity. This idea was also supported by the finding of a large amount of proteins in the medium when mutant cells had grown to stationary phase (Fig. $5 \mathrm{a})$. The pattern of proteins from the medium was similar to that of a cell-free extract (Fig. 5a), making it unlikely that the proteins found in the medium were a selected set preferentially secreted by the mutant. Leakage of proteins took place, although at a decreased level in media buffered at $\mathrm{pH} 5$ (Fig. 5b), suggesting that a certain loss of cell integrity already occurred at this $\mathrm{pH}$.

Addition of $1 \mathrm{M}$ sorbitol to the culture medium prevented aggregation, reduced permeability to propidium iodide (not shown) and leakage of proteins (Fig. 5b), suggesting an osmoprotective effect. However, it also lowered the final $\mathrm{pH}$ of the medium to values $<5$, so the prevention of aggregation could not unequivocally be ascribed to osmoprotection. Addition of $1 \mathrm{M} \mathrm{KCl}$ did not decrease the $\mathrm{pH}$ and prevented the cells aggregating and taking up propidium iodide, thus demonstrating that osmotic stabilization can remediate the phenotype caused by mutation. This result suggests that the Catps2/Catps2 mutant has a defect in the cell wall. Consistent with this idea was the increased sensitivity of the mutant to Zymolyase (results not shown).

Cells bearing the double Catps2/Catps2 disruption formed colonies with a smooth border on plates of Spider medium (Fig. 6) and when challenged with serum at $37^{\circ} \mathrm{C}$ showed a delay in the formation of hyphae. Both facts indicate that the mutation interferes with the correct filamentation process.

\section{Disruption of CaTPS2 decreases infectivity in mice}

Mice inoculated with the same amount of the Catps2/ Catps 2 disruptant and the wild-type showed a striking difference in their survival (Fig. 7). After 7 days no 


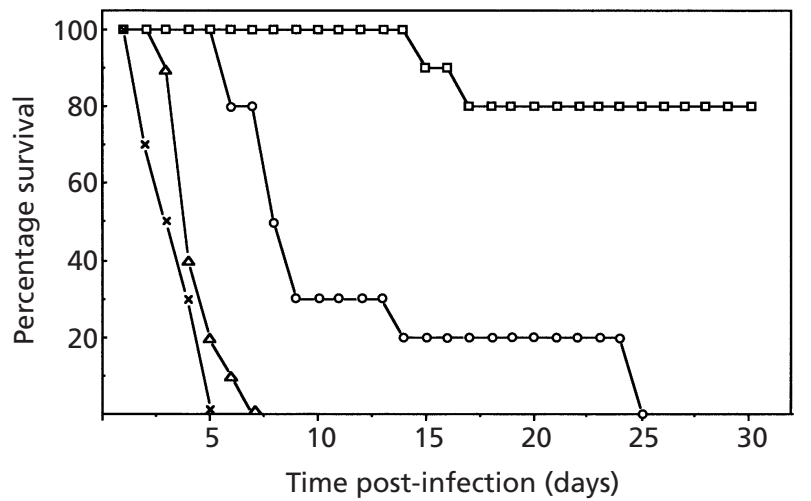

Fig. 7. Infectivity of C. albicans wild-type and Catps2/Catps2 mutant cells. Mice were inoculated as described in Methods with $1.5 \times 10^{6}$ c.f.u. of either wild-type (SC5314; $\triangle$ ), the CaTPS2/Catps2 heterozygote (LOZ184; O), the Catps2/Catps2 mutant (LOZ200; $\square$ ) or a Catps $2 /$ Catps2 mutant in which the CaTPS2 gene was reinserted (LOZ252; $\times$ ).

survivors were found in the group of mice inoculated with the wild-type, while after 1 month, $80 \%$ of those having received the injection of the double disruptant were alive (Fig. 7). When the CaTPS2 gene was reintroduced by way of plasmid pOZ11-6 (see Methods) in the Catps2/Catps2 strain, the strain regained infectivity and mice inoculated with the transformed strain died like those inoculated with the wild-type (Fig. 7). Mice inoculated with the heterozygous strain showed an intermediate behaviour (Fig. 7). The fate of the yeast in several organs was followed in mice inoculated in parallel. As shown in Table 2, after 1 month only a low fungal burden was found in the mice inoculated with the double disruptant. These mice were able to eliminate an important proportion of the infecting cells and those remaining did not significantly affect their survival.

\section{DISCUSSION}

We have cloned the CaTPS2 gene that encodes a T6P phosphatase and appears to play an important role in the determination of cell-surface properties and virulence. In Sac. cerevisiae and A. nidulans only one gene encoding this activity has been found and this also appears to be the case in C. albicans as shown by the lack of measurable trehalose and the increase in intracellular T6P concentration in the Catps2/Catps2 mutant.

The disruption of CaTPS2 did not cause a strong thermosensitive growth phenotype, even at $42^{\circ} \mathrm{C}$, and produced an aggregation of cells in the stationary phase. This is an important difference with the phenotypes reported for the tps 2 mutant of Sac. cerevisiae (De Virgilio et al., 1993) and of Sch. pombe (Franco et al., 2000) where no flocks have been observed and indicates that the accumulation of T6P acts differently in these organisms. The fact that aggregation in the Catps2/ Catps 2 mutant was apparent only in the stationary phase suggests that the increased levels of T6P influence processes taking place at this phase of growth when an important number of not yet well understood changes occur that affect different cell properties (WernerWashburne et al., 1996). Reports of flocculation in C. albicans mutants are scarce; among them one concerns a mutant in a two-component histidine kinase, CaHK1 (Calera \& Calderone, 1999), and another one, a mutant affected in the gene BGL2 encoding a glucosyl transferase (Sarthy et al., 1997). In the first case the aggregation is due to interactions between the hyphal surfaces, while in the second case no information about how the aggregation occurred is available. In the case of the aggregation observed in the Catps2/Catps2 mutant, hyphae were not seen when aggregation took place. Expression of ALS1, a gene that encodes an agglutinin (Hoyer et al., 1995), was similar in the wild-type and in the mutant (results not shown), suggesting that changes

Table 2. Distribution of C. albicans wild-type and Catps2/Catps2 mutant cells in different organs of mice at different times following inoculation

Mice were infected as described in Methods with either the wild-type (SC5314), the Catps2/Catps2 mutant (LOZ200) or a Catps2/Catps2 mutant in which the CaTPS2 gene was reinserted (LOZ252). At the times indicated the number of $C$. albicans cells per $g$ tissue was determined as described in Methods. Data represent the mean \pm standard error of at least three mice.

\begin{tabular}{|c|c|c|c|c|}
\hline \multirow[t]{3}{*}{ Organ } & \multicolumn{4}{|c|}{$\log ($ No. of $C$. albicans cells per g tissue) } \\
\hline & \multicolumn{3}{|c|}{3 days } & \multirow{2}{*}{$\frac{30 \text { days }}{\text { Catps2/Catps2 }}$} \\
\hline & Wild-type & Catps2/Catps2 & $\begin{array}{c}\text { Catps2/Catps } 2 \text { with } \\
\text { CaTPS } 2\end{array}$ & \\
\hline Kidney (right) & $5 \cdot 76 \pm 0 \cdot 42$ & $4 \cdot 16 \pm 0 \cdot 18$ & $6 \cdot 65 \pm 0 \cdot 151$ & $0.52 \pm 0.52$ \\
\hline Kidney (left) & $6 \cdot 54 \pm 0 \cdot 35$ & $3.74 \pm 0.57$ & $6 \cdot 67 \pm 0 \cdot 125$ & $2 \cdot 26 \pm 0 \cdot 92$ \\
\hline Spleen & $3 \cdot 53 \pm 0 \cdot 14$ & $3 \cdot 59 \pm 0 \cdot 34$ & $3 \cdot 76 \pm 0 \cdot 31$ & $1 \cdot 20 \pm 0 \cdot 59$ \\
\hline Liver & $2 \cdot 42 \pm 0 \cdot 13$ & $1 \cdot 48 \pm 0 \cdot 88$ & $3 \cdot 33 \pm 0 \cdot 40$ & $1 \cdot 09 \pm 0 \cdot 70$ \\
\hline Lung & $2 \cdot 63 \pm 0 \cdot 20$ & $2 \cdot 41 \pm 0 \cdot 95$ & $3 \cdot 19 \pm 0 \cdot 67$ & $0 \cdot 91 \pm 0 \cdot 60$ \\
\hline
\end{tabular}


in Als1 levels are not involved in the aggregation. A modification in hydrophobic properties of the cells could also occur in the mutant and determine its aggregation. The material that surrounded the aggregated cells of the Catps2/Catps2 mutant could have adhering properties that contribute to the aggregation of the cells. We do not know the nature of this material, but it is not too far fetched to think that its presence is a consequence of a defective cell wall. This idea is supported by the deaggregation of the flocks by a mild Zymolyase treatment.

The $\mathrm{pH}$ influence on aggregation could be explained by a difference in the charge of some proteins whose levels are changed in the Catps2/Catps2 mutant. The accumulated T6P could also have an effect on the expression of some $\mathrm{pH}$-regulated genes or on the activity of their products. It is well known that $\mathrm{pH}$ controls expression of different genes whose products are implicated in morphogenesis in C. albicans and that acidic $\mathrm{pH}$ favours the yeast form (El Barkani et al., 2000; Fonzi, 1999; Ramon et al., 1999). It is noteworthy that aggregation of the CaHK1 mutant also occurred at $\mathrm{pH} 7.5$ and not at acidic $\mathrm{pH}$ (Calera \& Calderone, 1999). In Sac. cerevisiae it has been found that cell wall organization is altered when the organism is faced with $\mathrm{pH}$ changes; at acidic $\mathrm{pH}$ values higher levels of certain cell-wall proteins were produced and resistance to lysis by $\beta$-1,3-glucanase increased (Kapteyn et al., 2001). The cell wall architecture of $C$. albicans has been shown to be similar to that of Sac. cerevisiae (Kapteyn et al., 2000), therefore it is not illogical to think that these changes may also occur in C. albicans and that they are altered in the Catps2/Catps2 mutant. That the changes are specifically related to the absence of an intact CaTPS2 and not to a lack of trehalose is shown by the fact that Catps1/Catps1 mutants did not aggregate nor showed changes similar to those shown by the Catps2/ Catps 2 mutant (Zaragoza et al., 1998).

Two facts support the conclusion that when Catps2/ Catps 2 cells enter stationary phase, they suffer an important loss of viability: the leakage to the culture medium of high amounts of proteins, most of them intracellular, and the permeability to propidium iodide. We could not quantify the loss of viability by colony counting because the aggregation produced highly variable counts. Again, lack of trehalose was not the cause of loss of viability as Catps1/Catps1 cells did not take up propidium iodide (unpublished results). The effects of the mutation are likely to be a consequence of defects in the cell wall as they are suppressed by osmotic stabilizers. Sorbitol also suppressed the phenotype of the CaHK1 mutant (Calera \& Calderone, 1999) and remediated the germination defect of conidia of $A$. nidulans orlA mutants defective in T6P phosphatase (Borgia et al., 1996). However, its action in the first case could be related to an inhibition of hyphal development (Alex et al., 1998), while in the second case it appears to be due to a stabilization of the cell wall weakened by a decreased chitin content. A decrease in chitin does not seem to be the cause of the increased permeability of the
Catps2/Catps2 mutant, since a decrease in chitin does not affect cell stability in C. albicans (Bulawa et al., 1995; Gow et al., 1994).

Our hypothesis is that the accumulation of T6P in the mutant is responsible for alterations in the architecture of the cell wall, a structure implicated in the maintenance of cell integrity and in interactions with other cells. Up to now the only role demonstrated for T6P outside the trehalose biosynthetic pathway is its inhibition of hexokinase (Blázquez et al., 1993); our results suggest other regulatory roles for this metabolite. In Sac. cerevisiae, tps1 mutants are not thermosensitive in permissive sources (unpublished data; Elliott et al., 1996), showing that a lack of trehalose is not the cause of the thermosensitive phenotype of $t p s 2$ mutants. These latter mutants accumulate T6P and it has been shown that a decrease in T6P intracellular accumulation suppresses their thermosensitive phenotype (Elliott et al., 1996), indicating that a high concentration of this metabolite interferes with normal cell growth as we have shown for the Catps2/Catps2 mutant. The possibility that T6P plays a role in the regulation of a cell integrity pathway cannot be ruled out.

The altered colony morphology found on Spider medium may be due to interference of the accumulated T6P with changes in cell wall composition that occur during this process (Schwartz \& Larsh, 1980). However, we cannot exclude that the protein Tps2 itself may have a direct effect on components of the pathway(s) that control hyphae formation.

The decreased infectivity of the Catps2/Catps2 mutant is clearly due to the lack of CaTPS2 and not to a secondary effect originated during the construction of the disrupted strain, as shown by the regain of infectivity of that strain when transformed with a plasmid bearing the CaTPS2 gene. Several causes may explain the greatly decreased infectivity of the Catps2/Catps2 mutant: a somewhat slower growth rate, defects in the cell integrity or impaired hyphae formation. Since a Catps1/ Catps1 mutant also has a lower infection potential (Zaragoza et al., 1998), the possibility that trehalose may be an important factor that protects $C$. albicans from some host defence mechanisms cannot be discarded. In fact, the Catps1/tps1 mutant appears to be highly sensitive to free radicals (J. C. Argüelles, personal communication), compounds that have been proposed to act as a host defence (Murphy, 1991).

Although the disruption of CaTPS2 did not cause a thermosensitive phenotype in C. albicans, the properties of the Catps2/Catps2 mutant and the absence of a trehalose biosynthetic pathway in mammals still make inhibitors of T6P phosphatase attractive candidates for antifungal therapy.

\section{ACKNOWLEDGEMENTS}

We thank C. R. Vázquez de Aldana, F. del Rey and A. Domínguez, (Salamanca, Spain) for help in electron microscopy and discussions, J. Pla, C. Nombela, J. F. García- 
Bustos (Madrid, Spain) and L. Hoyer (Ames, IO, USA) for C. albicans materials, J. C. Argüelles (Murcia, Spain) for communicating unpublished results, Juana M. Gancedo and María J. Mazón (Madrid, Spain), A. J. P. Brown (Aberdeen), A. Casadevall (New York, USA) and M. A. Blázquez (Valencia, Spain) for critical reading of the manuscript and CarmenLisset Flores (Madrid, Spain) for help with computer problems. This work was supported by grant PB97-1213-CO2 from the Spanish DGES. O.Z. was partially supported by a Fellowship from the Spanish PFPI.

\section{REFERENCES}

Alex, L. A., Korch, C., Selitrennikoff, C. P. \& Simon, M. I. (1998). COS1, a two-component histidine kinase that is involved in hyphal development in the opportunistic pathogen Candida albicans. Proc Natl Acad Sci U S A 95, 7069-7073.

Blázquez, M. A., Lagunas, R., Gancedo, C. \& Gancedo, J. M. (1993). Trehalose-6-phosphate, a new regulator of yeast glycolysis that inhibits hexokinases. FEBS Lett 329, 51-54.

Blázquez, M. A., Stucka, R., Feldmann, H. \& Gancedo, C. (1994a). Trehalose-6-P synthase is dispensable for growth on glucose but not for spore germination in Schizosaccharomyces pombe. J Bacteriol 176, 3895-3902.

Blázquez, M. A., Gancedo, J. M. \& Gancedo, C. (1994b). Use of Yarrowia lipolytica hexokinase for the quantitative determination of trehalose-6-phosphate. FEMS Microbiol Lett 121, 223-227.

Borgia, P. T., Miao, Y. \& Dodge, C. L. (1996). The orlA gene from Aspergillus nidulans encodes a trehalose-6-phosphate phosphatase necessary for normal growth and chitin synthesis at elevated temperatures. Mol Microbiol 20, 1287-1296.

Bulawa, C. E., Miller, D. W., Henry, L. K. \& Becker, J. M. (1995). Attenuated virulence of chitin-deficient mutants of Candida albicans. Proc Natl Acad Sci US A 92, 10570-10574.

Cabib, E. \& Leloir, F. L. (1958). The biosynthesis of trehalose-6phosphate. J Biol Chem 231, 259-275.

Calera, J. A. \& Calderone, R. (1999). Flocculation of hyphae is associated with a deletion in the putative CaHK1 two-component histidine kinase gene from Candida albicans. Microbiology 145, 1431-1442.

de Pauw, B. E. \& Meunier, F. (1999). The challenge of invasive fungal infections. Chemotherapy 45 (suppl. 1), 1-14.

De Virgilio, C., Bürckert, N., Bell, W., Jeno, P., Boller, T. \& Wiemken, A. (1993). Disruption of TPS2, the gene encoding the 100-kDa subunit of trehalose-6-phosphate synthase/phosphatase complex in Saccharomyces cerevisiae, causes accumulation of trehalose-6-phosphate and loss of trehalose-6-phosphate phosphatase activity. Eur J Biochem 212, 315-323.

Edwards, J. E. (1991). Invasive Candida infections. Evolution of a fungal pathogen. N Engl J Med 324, 1060-1062.

El Barkani, A., Kurzai, O., Fonzi, W. A., Ramon, A., Porta, A. Frosch, M. \& Muhlschlegel, F. A. (2000). Dominant active alleles of RIM101(PPR2) bypass the $\mathrm{pH}$ restriction of filamentation of Candida albicans. Mol Cell Biol 20, 4635-4647.

Elliott, B., Haltiwanger, R. S. \& Futcher, B. (1996). Synergy between trehalose and Hsp104 for thermotolerance in Saccharomyces cerevisiae. Genetics 144, 923-933.

Fonzi, W. A. (1999). PHR 1 and PHR 2 of Candida albicans encode putative glycosidases required for proper cross-linking of beta1,3- and beta-1,6-glucans. J Bacteriol 181, 7070-7079.

Fonzi, W. A. \& Irwin, M. Y. (1993). Isogenic strain construction and gene mapping in Candida albicans. Genetics 134, 717-728.
Franco, A., Soto, T., Vicente-Soler, J., Valero Guillen, P., Cansado, J. \& Gacto, M. (2000). Characterization of $t p p 1^{+}$as encoding a main trehalose-6-P phosphatase in the fission yeast Schizosaccharomyces pombe. J Bacteriol 182, 5880-5884.

François, J. M., Blázquez, M. A., Ariño, J. \& Gancedo, C. (1997). Storage carbohydrates in the yeast Saccharomyces cerevisiae. In Yeast Sugar Metabolism, pp. 285-312. Edited by F. K. Zimmermann \& K. D. Entian. Lancaster, Basel: Technomic Publishing.

Gietz, D., St Jean, A., Woods, R. A. \& Schiestl, R. H. (1992). Improved method for high efficiency transformation of intact yeast cells. Nucleic Acids Res 20, 1425.

Gietz, R. D. \& Sugino, A. (1988). New yeast-Escherichia coli shuttle vectors constructed with in vitro mutagenized yeast genes lacking six-base pair restriction sites. Gene 74, 527-534.

Gillum, A. M., Tsay, E. Y. \& Kirsch, D. R. (1984). Isolation of the Candida albicans gene for orotidine- 5 -phosphate decarboxylase by complementation of $S$. cerevisiae ura3 and E. coli pyrF mutations. Mol Gen Genet 198, 179-182.

Gounalaki, N. \& Thireos, G. (1994). Yap1, a yeast transcriptional activator that mediates multidrug resistance, regulates the metabolic stress response. EMBO J. 13, 4036-4041.

Gow, N., Robbins, P. W., Lester, J. W., Brown, A. J., Fonzi, W. A., Chapman, T. \& Kinsman, O. S. (1994). A hyphal-specific chitin synthase gene (CHS2) is not essential for growth, dimorphism, or virulence of Candida albicans. Proc Natl Acad Sci USA 91, 6216-6220.

Herbrecht, R., Letscher, V., Andres, E. \& Cavalier, A. (1999). Safety and efficacy of amphotericin B colloidal dispersion. A review. Chemotherapy 45 (suppl. 1), 67-76.

Herrero, A. B., López, M. C., Fernández-Lago, L. \& Domínguez, A. C. (1999). Candida albicans and Yarrowia lipolytica as alternative models for analysing budding patterns and germ tube formation in dimorphic fungi. Microbiology 145, 2727-2737.

Hill, J. E., Myers, A. M., Koerner, T. J. \& Tzagoloff, A. (1986). Yeast/E. coli shuttle vectors with multiple unique restrictions sites. Yeast 2, 163-167.

Hoffman, C. S. \& Winston, F. (1987). A ten-minutes DNA preparation from yeast efficiently releases autonomous plasmids for transformation of E. coli. Gene 57, 266-272.

Hoyer, L. L., Scherer, S., Shatzman, A. R. \& Livi, G. P. (1995). Candida albicans ALS1: domains related to a Saccharomyces cerevisiae sexual agglutinin separated by a repeating motif. Mol Microbiol 15, 39-54.

Kapitany, R. A. \& Zebrowsky, E. J. (1973). A high resolution PAS staining for polyacrylamide gel electrophoresis. Anal Biochem 56, 361-369.

Kapteyn, J. C., Hoyer, L. L., Hecht, J. E., Muller, W. H., Andel, A., Verkleij, A. J., Makarow, M., Van Den Ende, H. \& Klis, F. M. (2000). The cell wall architecture of Candida albicans wild-type cells and cell wall-defective mutants. Mol Microbiol 35, 601-611.

Kapteyn, J. C., ter Riet, B., Vink, E., Blad, S., De Nobel, H., Van Den Ende, H. \& Klis, F. M. (2001). Low external pH induces HOG1dependent changes in the organization of the Saccharomyces cerevisiae cell wall. Mol Microbiol 39, 469-479.

Kobayashi, N. \& McEntee, K. (1993). Identification of cis and trans components of a novel heat-shock stress regulatory pathway in Saccharomyces cerevisiae. Mol Cell Biol 13, 248-256.

Kohler, G. A., White, T. C. \& Agabian, N. (1997). Overexpression of a cloned IMP dehydrogenase gene from Candida albicans confers resistance to the specific inhibitor mycophenolic acid. J Bacteriol 179, 2331-2338. 
Kurtz, M. B., Cortelyou, M. W. \& Kirsch, D. R. (1986). Integrative transformation of Candida albicans using a cloned ADE2 gene. Mol Cell Biol 6, 142-149.

Laemmli, U. K. (1970). Cleavage of structural proteins during the assembly of the head of bacteriophage T4. Nature 227, 680-685.

Liu, H., Köhler, J. \& Fink, G. R. (1994). Suppression of hyphal formation in Candida albicans by mutation of a STE12 homolog. Science 266, 1723-1725.

Marchler, G., Schüller, C., Adam, G. \& Ruis, H. (1993). A Saccharomyces cerevisiae UAS element controlled by protein kinase A activates transcription in response to a variety of stress conditions. EMBO J 12, 1997-2003.

Martin, M. V. (1999). The use of fluoconazole and itraconazole in the treatment of Candida albicans infections: a review. J Antimicrob Chemother 44, 429-437.

Monk, B. \& Perlin, D. S. (1994). Fungal plasma membrane proton pumps as promising new antifungal targets. Crit Rev Microbiol 20, 209-223.

Murphy, J. W. (1991). Mechanisms of natural resistance to human pathogenic fungi. Annu Rev Microbiol 45, 509-538.

Negredo, A., Monteoliva, L., Gil, C., Pla, J. \& Nombela, C. (1997). Cloning, analysis and one-step disruption of the ARG5,6 gene of Candida albicans. Microbiology 143, 297-302.

Petit, T. \& Gancedo, C. (1999). Molecular cloning and characterization of the gene HXK1 encoding the hexokinase from Yarrowia lipolytica. Yeast 15, 1573-1584.

Petit, T., Blázquez, M. A. \& Gancedo, C. (1996). Schizosaccharomyces pombe possesses an unusual and a conventional hexokinase: biochemical and molecular characterization of both hexokinases. FEBS Lett 378, 185-189.

Ramon, A. M., Porta, A. \& Fonzi, W. A. (1999). Effect of environmental $\mathrm{pH}$ on morphological development of Candida albicans is mediated via the PacC-related transcription factor encoded by PRR2. J Bacteriol 181, 7524-7530.

Reinders, A., Bürckert, N., Hohmann, S., Thevelein, J. M., Boller, T., Wiemken, A. \& De Virgilio, C. (1997). Structural analysis of the subunits of the trehalose-6-phosphate synthase/phosphatase complex in Saccharomyces cerevisiae and their function during heat shock. Mol Microbiol 24, 687-695.

Sambrook, J., Fritsch, E. F. \& Maniatis, T. (1989). Molecular Cloning: a Laboratory Manual, 2nd edn. Cold Spring Harbor, NY : Cold Spring Harbor Laboratory.

Sarthy, A. V., McGonigal, T., Coen, M., Frost, D. J., Meulbroek, J. A. \& Goldman, R. C. (1997). Phenotype in Candida albicans of a disruption of the BGL2 gene encoding a 1,3- $\beta$-glucosyltransferase. Microbiology 143, 367-376.

Schwartz, D. S. \& Larsh, H. W. (1980). An effective medium for the selective growth of yeast or mycelial forms of Candida albicans: biochemical aspects of the two forms. Mycopathologia 17, 67-75.

Stratford, M. (1989). Yeast flocculation: calcium specificity. Yeast 5, 487-496.

Van Laere, A. (1989). Trehalose, reserve and/or stress protectant? FEMS Microbiol Rev 63, 201-210.

Varela, J. C. S., Praekelt, U. M., Meacock, P. A., Planta, R. J. \& Mager, W. H. (1995). The Saccharomyces cerevisiae HSP12 gene is activated by the high-osmolarity glycerol pathway and negatively regulated by protein kinase A. Mol Cell Biol 15, 6232-6245.

Verduyn Lunel, F. M., Meis, J. F. \& Voss, A. (1999). Nosocomial fungal infections: candidemia. Diagn Microbiol Infect Dis 34, 213-220.

Werner-Washburne, M., Braun, E. L., Crawford, M. E. \& Peck, V. M. (1996). Stationary phase in Saccharomyces cerevisiae. Mol Microbiol 19, 1159-1166.

Wright, R., Basson, M., D’Ari, L. \& Rine, J. (1988). Increased amounts of HMG-CoA reductase induce 'karmellae': a proliferation of stacked membrane pairs surrounding the yeast nucleus. J Cell Biol 107, 101-114.

Zaragoza, O., Blázquez, M. A. \& Gancedo, C. (1998). Disruption of the Candida albicans TPS1 gene encoding trehalose-6-P synthase impairs formation of hyphae and decreases infectivity. J Bacteriol 180, 3809-3815.

Received 29 November 2001; revised 15 January 2002; accepted 28 January 2002. 